\title{
La taqiyya en las fuentes cristianas: indicios de su presencia entre los moriscos
}

\author{
Taqiyya in Christian Sources: Evidences of \\ its Existence among the Moriscos
}

\author{
Diego Rubio \\ Magdalen College, University of Oxford, Reino Unido
}

\begin{abstract}
Es habitual remitirse a la taqiyya para explicar la actitud religiosa de los moriscos y el fracaso de las políticas asimiladoras. En los últimos años, sin embargo, varios investigadores han puesto en tela de juicio esta interpretación. Tres han sido sus argumentos: la ausencia del término en los textos hispánicos, la escasez de literatura jurídica que lo justifique y la condición sunní de los musulmanes españoles. Refutar algunos de estos razonamientos escépticos es el objetivo de este breve artículo. Para ello menciono varios textos peninsulares de la época que, sin emplear este mismo término, sugieren que los moriscos conocieron y abrazaron tal doctrina.
\end{abstract}

Palabras clave: moriscos; taqiyya; disimulación; simulación.
It has been commonplace to employ taqiyya to explain the religious beliefs of the Moriscos and the failure of assimilation. However, in recent years, renowned scholars have questioned this interpretation using three arguments: the absence of the term in Hispanic texts; the lack of legal literature that supports it; and the Sunni beliefs of the Spanish Muslims. The aim of this brief article is to refute some of these sceptical thoughts. For this, I mention several Christian sources of the period that, without using this particular term, suggest that the Moriscos knew about and embraced this doctrine.

Key words: Taqiyya; Dissimulation; Simulation.

Ciertas corrientes del Islam permiten a sus fieles faltar al cumplimiento de los preceptos religiosos cuando está en peligro su vida, que es el bien más valioso que Dios ha otorgado a los hombres. Esta dispensación teológica recibe, entre otros, el nombre de taqiyya (takiyye, tuqā $h . .$.$) , palabra que deriva de la voz árabe ittaqà, que puede traducirse$ por «temor», «precaución» o «protección» en su forma más reverencial. La singularidad de esta doctrina es más evidente que su labor o su empleo. Sin demorarnos demasiado en los detalles, conviene recordar los dos conceptos -aparentemente contradictorios-que concilia: de un 
lado, la hipocresía ${ }^{1}$; de otro, la salvación del alma. Acogiéndose a este principio, el musulmán que se hallara en peligro podía 1) abstenerse de practicar el Islam en público (disimulación), y 2) adoptar exteriormente la religión del grupo dominante (simulación) ${ }^{2}$. Lo único que debía hacer era conservar la fe islámica en su interior ${ }^{3}$.

El primero en asociar esta doctrina al caso morisco fue el hispanista británico Leonard Patrick Harvey, a comienzos de los años sesenta ${ }^{4}$. Como él mismo reconocería después, al hacerlo «era nerviosamente consciente de estar innovando $»^{5}$. La idea fue bien recibida, aunque no acabó popularizándose hasta una década después, con la publicación del libro Morisques et Chrétiens: un affrontement polémique (París, 1977) del hispanista francés Louis Cardaillac. A raíz del mismo, la mención de la taqiyya se propagó rápidamente hasta convertirse en una especie de referencia obligada en todos los artículos sobre moriscos y en una de las explicaciones de por qué fracasó la asimilación de esta

${ }^{1}$ El DRAE define «hipocresía» como el «fingimiento de cualidades o sentimientos contrarios a los que verdaderamente se tienen o experimentan». Entre la abundante bibliografía que existe sobre este término, recomiendo la lectura de los artículos de Frederic Amory ("Whited Sepulchres", pp. 5-17) y Jacques Bos ("The Hidden self of the hypocrite", pp. 65-84). Como señala este último, «in the seventeenth-century [...] the term hypocrisy was primaly used in a religious sense, denoting the vicious feigning of piousness» (p. 67).

${ }_{2}$ Conviene precisar ambos conceptos. La «disimulación» es la acción que consiste en no mostrar lo que se es (supressio veri); la «simulación» consiste en mostrar lo que no se es (suggestio falsi). Lo uno remite a un ocultamiento; lo otro a una fícción. El primero está emparentado con la cautela; el segundo es una forma de impostura. Para el Diccionario de autoridades, simular es «Representar alguna cosa, fingiendo o imitando lo que no es» (1739, t. I, p. 118). Para Alonso de Palencia, «Simular es mentir, fingir lo que no es, fazer algo con engaño: simulamos lo no sabido y disimulamos lo sabido. Simulare por dezir lo verdadero por falso (...) Dissimulare: mostrar non ser lo que es» (Universal vocabulario en latín y en romance, t. II, f. CCCCLVv). Estos términos han recibido un trato diverso a lo largo de la historia (véase, por ejemplo, Cavaillé, "Simulatio/dissimulatio", pp. 115-131 y Houdt, "Word Histories, and Beyond", pp. 1-31). Diferenciados y distinguidos por unos, considerados sinónimos por otros, lo cierto es que remiten a acciones íntimamente ligadas entre sí que, en el caso morisco, no pueden darse la una sin la otra. Así las cosas, de aquí en adelante me referiré a ambas simultáneamente empleando el neologismo acuñado por Jean-Pierre Cavaillé «di/simulación» para hacer más cómoda la lectura y evitar la tradicional ambigüedad conceptual.

${ }^{3}$ Según Jomeini (Risāla fi l-taqiyya, p. 175), la taqiyya permite al creyente cometer actos prohibidos (fi l-muharram), omitir deberes obligatorios (tark wāyib), prescindir de ciertos requisitos que demanda el ritual (tark šart aw ŷyz') y hacer otras cosas que la situación requiera.

${ }^{4}$ Harvey, "Crypto-Islam in Sixteenth Century Spain", pp. 163-178.

${ }^{5}$ Harvey, "Una referencia explícita a la legalidad de la práctica de la taqiya por los moriscos", p. 561. 
minoría. Una referencia eternamente superficial, en cualquier caso. En los últimos cuarenta años, la mayoría de los historiadores han mencionado la taqiyya en sus trabajos, pero ninguno ha profundizado en ella. El propio Cardaillac la trató de forma tangencial, dedicándole apenas catorce páginas de su obra ${ }^{6}$.

Algunos investigadores, sensibles a este hecho, han lamentado el uso indiscriminado del término y sugerido que «debería ponerse en cuarentena crítica» ${ }^{7}$. Según Bernard Vincent, «desde hace veinte años se ha querido ver en la taqiyya el medio utilizado por todos los moriscos para preservar lo esencial. La minoría habría sido invariablemente adepta a la resistencia pasiva. Se olvida que la taqiyya no tenía la aprobación unánime en el medio musulmán o criptomusulmán. Es hora de relativizar la importancia de la práctica de la taqiyya, que no es más que un mal menor» ${ }^{8}$.

Otros han ido más lejos. María Jesús Rubiera Mata propuso el «destierro total» del concepto. Argumentó que la taqiyya era un principio exclusivamente šíí y que, como tal, no pudo ser conocido ni practicado por los moriscos, que eran sunníes. Éstos - escribió- «utilizaron el nicodemismo, como otros grupos religiosos, pero no la taqiyya, cuyo nombre incluso desconocían ${ }^{9}$. Sus palabras reflejan bien el pensamiento de muchos autores que han rechazado la existencia de la taqiyya en la Península arguyendo tres razones: la ausencia del término en los textos hispánicos, la escasez de literatura jurídica que lo justifique y la condición sunní de los musulmanes españoles.

Refutar algunas de estas interpretaciones escépticas es el objetivo de esta breve nota. Para hacerlo podrían esgrimirse varios argumentos. Podría recordarse, de entrada, que la di/simulación prudencial no fue una prerrogativa exclusiva del šî́ísmo ${ }^{10}$; que, de hecho, fue consentida

6 Traducido al castellano como Moriscos y cristianos: un enfrentamiento polémico: (1492-1640), Madrid, Fondo de Cultura Económica, 1979, interesan las pp. 85-98. Del mismo autor, véase también "Un aspecto de las relaciones entre Moriscos y Cristianos", pp. 107-122.

${ }^{7}$ García Pedraza, Actitudes ante la muerte en la Granada del siglo XVI, t. I, p. 109.

8 Vincent, El Río morisco, p. 136.

9 Rubiera Mata, "Los moriscos como criptomusulmanes", pp. 545-547 y Rubiera Mata, "La taqiyya y la fatua del Muftí de Orán".

10 «Dissimulation is not peculiar to Imami Shiism, and is attested among various Muslim individuals or groups espousing minority views» (Kohlberg, "Taqiyya in Shīei Theology and Religion", p. 361). 
y practicada por numerosas sectas islámicas en el devenir de los siglos, como jāriŷíes ${ }^{11}$, ismāeilíies ${ }^{12}$, șūfíes ${ }^{13}$ y, lo que es más importante, los propios sunníes ${ }^{14}$. Podría argumentarse, también, que no corresponde a las autoridades del fiqh, sino a cada creyente, determinar cuándo es legítimo el disimulo. Podría advertirse, por último, que existen varios textos elaborados en el entorno morisco -como la fatwà del Muftí de Orán o el Sumario del Mancebo de Arévalo- que, sin emplear el término taqiyya, postulan la presencia de esta creencia en España. Desgraciadamente, aquí carezco del espacio necesario para desarrollar tales ideas, por lo que, en esta ocasión, me limitaré a abordar el asunto desde un solo frente: el de las fuentes cristianas.

En efecto, para probar que los moriscos recurrieron a la taqiyya no es necesario adentrarse en sutilezas teológicas ni en el análisis minucioso de los textos islámicos. Basta evocar los numerosos testimonios cristianos que denunciaron su uso; testimonios escritos en la época por

11 Véase, entre otros: Kohlberg, "Taqiyya in Shīē Theology", p. 361; Stewart, "Taqiyyah as Performance", pp. 1-70; Stewart, "Documents and Dissimulation", pp. 569598 y Straface, "La Taqiyya nell'Islam”, pp. 215-217.

${ }_{12}$ Steigerwald, "La dissimulation (taqiyya) de la foi dans le shīeisme ismaélien", pp. 39-59 y Daftary, The Ismailis: Their History and Doctrines, index taqiyya.

${ }_{13}$ Tras la ejecución de al-Husayn b. Manșūr al-Ḥallāŷy (m. 922), líder legendario de la mística musulmana, el sufismo viró hacia la discreción y el secreto (para una historia de este proceso véase Ernst, Words of Extasy in Sufism, pp. 97-117). Según Schimmel, los sufíes cultivaron en diversas ocasiones el «silence and secrecy [...] to escape persecution in times of political restlessness [...] We may compare their attitude in a certain way to that of the Shiites who used taqiya (dissimulation) throughout all the centuries» (Schimmel, "Secrecy in sufism", p. 84).

${ }_{14}$ Al-Sarajsī (Al-Mabsūt, pp. 47-49) o Abū 'Abd Allāh Muhammad al-Qurțubī (alŶămi' li-ahkām al-Qur'ān, vol. IV, p. 57) autorizaron el empleo de la taqiyya, siempre y cuando fuese para evitar un peligro de muerte y no otro tipo de daño. Esta dispensación tuvo su eco en la historia. Cuando el califa 'abbāsí al-Ma mūn (m. 833) hizo de la doctrina mu tazilí del "Corán creado" un dogma de Estado, numerosos sabios sunníes tuvieron que comparecer ante el tribunal de la Mihna (827-847) y proclamar solemnemente que reconocían tal principio. Algunos usaron ciertas astucias para ello (un creyente designó su dedo, que apuntaba al Corán, diciendo «éste está creado»), pero la mayoría de jurisconsultos lo hizo recurriendo a la taqiyya. Del mismo modo actuaron los aš aríes que, durante el sultanato de Mas ūd I (1030-1040), se fingieron hanafíes para no ser ejecutados por los soldados turcos (Madelung, "The Spread of Maturidism and the Turks", pp. 109-168). O los sunníes de la antigua Persia cuando la dinastía Safawì (1501-1722) impuso el šî́ ísmo como religión oficial del Estado (Dickson, Shah Tahmasp and the Uzbeks, pp. 192-193). Podrían citarse otros ejemplos con nombres y apellidos, algunos de ellos coetáneos de los moriscos (vid. Kohlberg, "Taqiyya in Shīì Theology", p. 361). Por tanto, la condición sunnita de los musulmanes españoles no impide que éstos conocieran -y reconocieranla taqiyya. 
personas que convivieron y trataron de cerca a esta minoría; testimonios que, sin emplear la palabra taqiyya, demuestran que los moriscos conocían la existencia de una doctrina islámica que legitima el disimulo religioso ${ }^{15}$. Citaré solo algunos, en orden cronológico.

En 1587 el Obispo de Segorbe escribió a Felipe II para explicarle los problemas que estaba encontrando en las campañas de evangelización. Entre otros obstáculos, señaló el siguiente:

Es cosa llana y certissima que todos los moros de España, y fuera della, por tradición de vnos a otros y por la doctrina y enseñamientos de sus alfaquies y maestros, tienen entre ellos por fee que si por escusar alguna violencia o por temor de alguna pena reserven el baptismo de los christianos o confiessan a ihu-xpo o hacen alguna otra obra christiana, no ofenden a mahoma si en sus corazones le creen, aman y adoran $[\ldots]$

Item [...] y que orar de entrambos ritos no quebranta la secta de mahoma specialmente reteniéndola en el corazón y haciendo algunas de sus cerimonias secretamente, por concurrir alguna violencia o temor de pena, y, por esta razón, con facilidad piden y resciven el baptismo de los christianos y confiesan exteriormente la fee de ihu-xpo ${ }^{16}$.

\section{De forma parecida, en 1606 Pedro de Valencia escribió:}

Así Mahoma manda a los suyos que se amen y hagan bien unos a otros entre sí, pero que aborrezcan y maltraten a todos los que no fueren de su secta y, para que los suyos no pudiesen ser semejantemente compelidos con violencia y temor a dejar su ley, inventó una maquina diabólica, y es que les concede a los moros que, si les hicieren fuerza y corrieren riesgo por la profesión de su ley, la nieguen libremente, y coman puerco y las demás cosas vedadas y hagan cualesquiera muestras

${ }^{15}$ No debe sorprender que sea en las fuentes cristianas y no en las moriscas donde encontremos las huellas más claras de la taqiyya. Al fin y al cabo, la mayoría de las cosas que sabemos sobre esta minoría provienen de estas fuentes.

${ }_{16}$ Parescer de don Martín de Salvatierra, obispo de Segorve, del Consejo del R.N.S. dado por mandado de su magestad... acerca del estado en que están los moriscos del reyno de Valencia y de la reformación en instrucción que se trata de darles, 30 de julio de 1587, Ms. 5785 de la Biblioteca Nacional de Madrid. Documento recogido en Boronat y Barrachina, Los moriscos españoles y su expulsión, vol. I, pp. 618-619. Se podrían citar más fragmentos del texto: «Item, se confirma mas esto y la notable burla y menosprecio que todos ellos hacen de la religion xpiana [...], y procuran ser compelidos y apremiados a hacer estas obras christianas con injuria suya porque tienen en doctrina de sus maestros y antepasados que en ello ganan gran merito delante de mahoma y que pueden exteriormente negar a mahoma reteniéndole en sus coraçones...» (p. 622). «Item, como esta dicho tienen por fee y por doctrina [...] que si se les hiciere alguna fuerça o violencia para haverla de negar [su secta], la pueden negar, retiniendola en el coraçon questo les basta para se salvar» (p. 623). 
exteriores de negación, sin que por esto incurrieran [en] infidelidad ni culpa alguna $^{17}$.

Declaraciones semejantes encontramos en los escritos de Damián Fonseca, dominico portugués que vivió en primera persona la Expulsión. Fonseca reconoce que algunos moriscos daban muestras de cristiandad al verse amenazados, aunque

todo era ficcion permitida en su ley, pues consiente, que la puedan negar con la boca sus profesores, guardandola empero en el coraçon; y les da licencia, que pregonen la de Christo si fueren forçados a ello, como selo enseño Mahoma; siguiendo la heregia de los que dezian, que era licito negar a Dios en los tormentos; y por esso se contentò que los suyos le honrassen en el coraçon, aunque por miedo de los tormentos le negassen: en la qual doctrina los instruhian los Alfaquies que passauan de Africa al Reyno de Valencia para enseñarles el Alcoran ${ }^{18}$.

Quiero recordar un último ejemplo, algo más tardío. En la Biblioteca de la Real Academia de la Historia se conserva un manuscrito en $4^{\mathrm{o}}$ con la intitulación La conversión de los moros. Debió de escribirlo el Padre Juan de Almarza, jesuita que se afanó en la evangelización de los moriscos esclavos que quedaron en Murcia tras la Expulsión ${ }^{19}$. Uno de los capítulos está dedicado a impugnar «el que se pueda negar la verdadera religión en lo exterior». Según Almarza:

Enseña Mahoma en su Alcoran [...] que un Mahometano puede en lo exterior por temor de algún mal fingir otra ley de la que tiene en el corazón: de suerte que si teme que le vendrá algún daño por decir que es Moro, puede decir que no es Moro: y puede por la misma razón bautizarse, y confesarse, aunque bautizándose y confesándose de a entender que es Cristiano, y por el consiguiente que no es Moro. La razón, que se fundan es, en que Dios solamente se paga del corazón: y así que

17 Tratado acerca de los moriscos de España, 1606. BNM, Ms. 7.845, ff. 4r-42v. La cita en f. 5v. La misma idea aparece en el f. 8r: «No quieren honra más que con su pueblo y nación, y ésa ganan con mostrarse moros, y la perdieran con lo contrario: pero cuando llegan a correr riesgo la vida o la hacienda, como saben que Mahoma no quiso mártires ni esperó que ninguno hubiese de querer morir por su mentira, niegan luego y dicen ser o querer ser cristianos, sin por ello perder la fe con Mahoma ni la honra con los suyos, ni dejar de ser moros como antes. Fue diabólica traza ésta, como he dicho, y que nos causa grande perplejidad y descomodidad, si nunca nos habemos de poder asegurar de su fe, por más que digan o desdigan; pero queda la seña cierta y a que sólo se debe advertir: Ex operibus eorum cognoscetis eos, y esto no se halla jamás en ellos» (Vid. la ed. de González Cañal, Obras completas, vol. IV, pp. 67-139).

${ }_{18}^{18}$ Fonseca, Iusta expulsión de los moriscos de España, pp. 112-113.

19 Cassani, Glorias del segundo siglo de la Compañia de Jesús, t. III, pp. 712-725. 
como tengan en el corazón la ley de Mahoma, no importa que la nieguen con la boca, o con las acciones, cuando de confesarla se le sigue algún daño: y así que no pecan, aunque la nieguen en lo exterior, como la confiesen en lo interior. La cual doctrina la abrazan de tal manera los Mahometanos, que no solo por no perder la vida, sino por un pequeño interés se hacen Cristianos de cumplimiento, confesando con las palabras, y con las acciones que lo son, y quedandose en el corazón Moros, sin que en esto les parezca a ellos que pecan ${ }^{20}$.

Podría mencionar más textos como los de Jaime Bleda ${ }^{21}$, Juan Use$\operatorname{ros}^{22}$ o Marcos Guadalajara ${ }^{23}$ que denuncian el uso de la taqiyya. Sin embargo, algún retórico argumentaría - no sin razón- que los escritos apologéticos no son del todo fiables; que tales acusaciones no se refieren a una práctica real, sino a un mero argumento polémico. Yo descreo de esa interpretación; por ello, deseo evocar dos fuentes más, de naturaleza diversa.

La primera es el Catechismo de Martín de Ayala (1599). Esta obra consagra un diálogo entero -el XVIII del Libro primero- a demostrar «quan flaca y falsa es la secta de Mahoma, pues concede a los Moros que por miedo de los peligros confiessen en lo exterior otra ley de la que tienen interiormente» ${ }^{24}$. El Discípulo (es una convención injusta del género que él encarne la ignorancia) pregunta al Maestro:

Desseo mejor entender lo que dixisteys de la constancia de los moros: que dezis que ni Mahoma la enseño, ni los Moros la tienen porque fingen en lo exterior otra ley dela que creen interiormente; y aprueuan por esta ley corrupta no ser mala esta fiction. Yo antes he visto que todos ellos presumen mucho de constantes, y por

20 Almarza, Juan de, La conversión de los moros, RAH, Ms. 9/2263, ff. 156r-156v.

${ }^{21}$ Según este autor, «...todos los novencientos años que [los moriscos] vivieron en España, estuvieron generalmente tercos, y pertinaces en la observancia y superstición Mahometana [...] fue la conversión solamente exterior en los mas, aparente y fingida, como las de otros de su nación, usando de la licencia que les da su misma ley» (Bleda, Crónica de los moros de España, p. 757).

${ }^{22}$ «No obstante que en lo afuera daban algunos indicios de Cristianos, como su falso Profeta se lo permite [...] estos malditos moriscos guardaban puntualmente todos los ritos mahometanos y se comunicaban con los moros de África...» (Useros, Compendio de la destruyçion de España hecha por los moros, Universidad de Valladolid, Ms. 385, f. 152r. Otra referencia en f. 158r).

${ }^{23}$ «Solo quiero decir de paso; que con el permiso y licencia que su maldita Secta concedía: que en ocasiones forzosas pudiesen fingir en lo exterior, y sin pecar qualquier Religión; con tal empero que conservasen su corazón para su falso y embaydor Profeta: vimos morir tantos de ellos adorando la Cruz, y hablando bien de nuestra Religión Católica, siendo en lo interior finos Mahometanos» (Guadalajara, Memorable expulsión y iustíssimo destierro de los moriscos de España, ff. 159r-159v).

${ }^{24}$ Ayala, Catechismo para instruccion de los nueuamente conuertidos de moros. Vid. También García Cárcel, "Estudio crítico del catecismo de Ayala-Ribera”, pp. 159-168. 
hazer ello no se tienen en menos; porque parece que el miedo es justa escusa para fingir otra cosa de lo que son, y yo siempre he oydo dezir, que Dios se paga de solo el corazon.

MAESTRO: Ello es certisimo que Mahoma lo enseño assi, y sus sequazes los siguen y hazen a la letra como el lo enseño: y si alla en aquellas partes de allende no se vee esto, es porque no se ofrecen ocasiones de temor para examinarse esto. Pero aca donde parece que auenturan algo en confesar que son Moros, y les conuiene fingir en lo exterior ser Christianos [...] fingen lo que no son, y niegan la ley que tienen en el corazon, y en solo lo exterior guardan la ley Christiana que han recebido, guardando el corazon para Mahoma y al demonio. Lo qual es cosa muy reprovada en negocios que tocan a Dios, porque el quiere todo el hombre, y el servicio entero y perfecto con todas las potencias interiores y exteriores. Y para que entiendas de rayz de donde tuuo origen este error, sabete que en tiempo deste falso propheta aun reynaua vna heregia que hauia comenzado en tiempos de los Martyres, que enseñaua que era licito en los tormentos negar a Dios; que era como dezir, que se cumplia con tener en el corazon a Dios y a su ley, y aunque por miedo exteriormente se negasse, no era pecado ${ }^{25}$.

Otra prueba notable de que la taqiyya era conocida por cristianos y moriscos la encontramos en el Catecismo del Sacromonte, escrito en Granada a finales del siglo $\mathrm{XVI}^{26}$. Como el anterior, este texto se estructura a modo de diálogo entre un Sacerdote y un joven morisco recién convertido:

SACERDOTE. ¿Qué hacen [los moriscos] para agradar a Dios?

Novicio. Lo que les enseñó Mahoma que le tienen por Profeta.

S. ¿Qué les enseñó Mahoma?

N. Enseñoles que se circuncidasen y ayunasen el Rabadán y otras muchas cosas que ignoran.

S. ¿Hacen eso?

N. No lo hacen. Unas cosas dejan de hacer por temor de los cristianos, y otras porque no las saben.

S. Luego ninguna ley tienen ni guardan [añadido al margen: Los moriscos ni saben la ley de Mahoma ni la guardan toda y por el consiguiente no se salvarán ni basta decir que en caso de violencia basta con tenerla en el corazón.] y por consiguiente no se salvan pues son con estos contrarios a todo el mundo, donde vemos que cada una de las criaturas tiene una ley.

N. La de los cristianos no quieren; la de los moros no pueden, y así es verdad que

25 Ayala, Catechismo para instruccion de los nueuamente conuertidos, pp. 132-134.

${ }^{26}$ Este Catecismo anónimo fue escrito a finales del XVI y principios del XVII. Ocupa los folios 1r-149v de un voluminoso legajo conservado en la Biblioteca de la Abadía del Sacromonte de Granada y ha sido editado por Luís Resines. Interesan sobre todo los capítulos $1-7$ y 48 . 
viven sin ley; pero tienen para sí que en caso de violencia pueden con tener en el corazón que son moros, aunque otra cosa digan de fuera, les bastará para salvarse. S. Saben de cierto que eso enseña la ley de Mahoma.

N. Así dicen comunmente los moros ${ }^{27}$.

No se requieren muchos comentarios. Todo se explica -creo- a la luz de los párrafos anteriores. Los textos citados no se limitan a denunciar la di/simulación morisca; todos apuntan la existencia de una «doctrina» concreta. Una «licencia» de origen islámico («que les da su misma ley») que, transmitida «por tradición» y «enseñamientos», permite al musulmán di/simular siempre y cuando 1) exista una situación de peligro «ocasiones de temor» y 2) «crea interiormente» en Alá, ya que 3) «Dios se paga de solo el corazón». Es importante notar que esta secuencia de pensamiento no es una invención cristiana. En ella se evocan exactamente los mismos condicionantes y argumentos con los que los autores šîíies - pero también sunníes y de otras sectas- justificaron la taqiyya en Oriente: 1) la situación de riesgo y necesidad (darūra), 2) la preeminencia de la intención (niyya) frente al acto ('amal) y 3) la capacidad divina de escrutar los corazones más allá de las apariencias ${ }^{28}$.

${ }^{27}$ Feria, Catecismo del Sacromonte, ff. 5v-6r. Más adelante (ff. 7r-7v), el Sacerdote retoma el asunto: «S. Tornemos ahora a lo que tratamos de los moriscos que con el corazón son moros y con la boca dicen que son cristianos y no saben ni guardan ley alguna. ¿Qué te parece desto? N. La ley de Mahoma da esa licencia que siendo violentados puedan con esa disimulación salvarse. S. ¿Por qué? N. Por salvar la vida y salud y porque no padezcan trabajos. S. Luego esa ley más cuida la vida, salud y hacienda del modo que a Dios, que da licencia de quebrantar su ley para no perder la vida. N. No hallo qué responder a eso, sino que no se ofenden a Dios en quebrantarse la ley en tal caso. S. Si no se ofende a Dios en quebrantarse, luego no es ley de Dios, porque todos lo que quebrantan la ley de Dios, a Dios injurian y ofenden. N. Dice la ley que eso es cuando pueden guardarla sin peligro de muerte, o perdida de salud o de hacienda».

${ }^{28}$ Quien estudie los tratados orientales que consienten la di/simulación religiosa encontrará los mismos argumentos. Todos aluden, por ejemplo, al condicionante de la «extrema necesidad» (darūra), y citan pasajes coránicos como la sura de la abeja que reconocen esta salvedad: «Aquél que reniega de Dios después de haber creído -no aquél que padece una persecución y cuyo corazón permanece en paz en la fe-, aquél que deliberadamente abre su corazón a la incredulidad, la cólera de Dios será sobre él y un terrible castigo le esperará» (XVI:106). Dios amenaza a los apóstatas, pero exime a aquellos que son perseguidos. Algo semejante se postula en la sura tercera: «Que no tomen los creyentes como amigos a los infieles en lugar de tomar a los creyentes - quien obre así no tendrá ninguna participación en Alá-, a menos que tengáis algo que temer de ellos» (III:28). La misma idea aparece en numerosos hadices. Por ejemplo, el hadī de Hišām b. Sālim afirma: «Oí a Abū 'Abd Allāh que dijo: Hay algo oculto de los siervos de Allāh que Le es apreciado. Dije: ¿De entre lo [que está] oculto? Y Él dijo: El disimulo» (Al-'Āmilī, Wasă’il al-Šsi 'a, 
En otras palabras, los textos citados sugieren que los cristianos conocían bien la taqiyya: no sólo su existencia, sino también los principales fundamentos con la que ésta era legitimada en la tradición jurídica más clásica. Y si la conocían «ellos» (esto es, religiosos cristianos con una cultura limitada y un conocimiento muy superficial, a veces casi inexistente, de la lengua árabe y la teología islámica), ¿debemos pensar que no la conocía «ningún» morisco? ¿Ni siquiera aquellos alfaquíes que hablaban árabe, poseían libros y mantenían contactos fluidos con los musulmanes del Magreb? Es un pensamiento osado, tanto más cuando varios de los escritos mencionados -los catecismos- estaban destinados a adoctrinar y lograr la conversión de estos mismos moriscos. ¿Por qué combatir argumentos que ellos ni siquiera conocían?

Algunos sostendrán que los cristianos crearon -inventaron- la existencia de esta dispensación islámica para emplearla como argumento polémico contra los moriscos, sin saber, ni los unos ni los otros, que tal dispensación realmente existía. No obstante, ésta me parece una interpretación inverosímil y forzada, más preocupada por llevar la contraria que por vislumbrar lo acontecido. En mi opinión, es más razonable pensar que los moriscos conocieron la taqiyya. Esto es, que conocieron el principio doctrinal islámico que permite el disimulo bajo circunstancias de peligro a condición de que se guarde la «Verdadera Fe» en el interior. Lo conocieron y, por tanto, lo tuvieron en mente mientras rezaban fingidamente en la Iglesia, comían tocino en casa de sus vecinos cristianos o renegaban del Profeta ante los inquisidores.

Ciertamente, ninguna de estas actitudes fue exclusiva de los moriscos. El siglo XVI -escribió Montaigne- fue el siglo de la disimulación ${ }^{29}$. La construcción de los Estados Modernos, la aparición de las monarquías absolutas, la emergencia del individualismo, la crisis del Humanismo, las transformaciones espirituales y religiosas provocadas

11, sec. 24, hadīt n. ${ }^{0}$ 14). Y en los tratados clásicos de sabios š̌i íes como Šayj al-Mufìd (m. 1022) (Tașhīh al-i 'tiqād fì șawāb al-intiqād aw šarh 'aqā'id al-ṣadūq, pp. 115-116) o Nașîr al-Dīn al-Ṭūsī (m. 1274) (Taljịs al-Muhașṣal, pp. 181-182). Para justificar esta idea, los autores orientales suelen remitirse a un dogma indiscutible: el de la omniscencia divina, evocando los numerosos pasajes coránicos que la postulan. Por ejemplo: «Da lo mismo si ocultáis vuestras creencias o las declaráis públicamente, Él tiene en verdad pleno conocimiento de lo que hay en [vuestros] corazones» (LXVII:13) (Sobre este asunto, véase Khan, Self and Secrecy in Early Islam, pp. 12-19).

${ }^{29}$ «La dissimulation est des plus notables qualités de ce siècle» (Essais, libro II, cap. XVIII). 
por la Reforma y la Contrarreforma... indujeron al hombre moderno a refugiarse en sí mismo, a proteger su identidad tras un muro de prudencia y secreto, asegurándose de ese modo una mínima parcela de libertad interior.

Para llevar a cabo este complejo y secular proceso, los individuos recurrieron a diversos mecanismos. Uno de ellos, acaso no el menos importante, fue la di/simulación. Debatida -admirada y refutada- como eterno problema del hombre, clave de la relación entre apariencia y realidad, entre mentira y verdad, la di/simulación pasó a convertirse en un elemento central de la vida política, religiosa y cultural del periodo. El fenómeno se aprecia en todas las esferas sociales ${ }^{30}$ : desde la solitaria figura del Príncipe, que se ve compelido a disimular por el bien de la República, hasta el campesino más miserable, acusado de profesar creencias heréticas, pasando por el artista, el eclesiástico y el cortesano, decidido a medrar en el «teatro del Mundo» ${ }^{31}$. La di/simulación se convirtió así en un tema privilegiado de la literatura política y moral ${ }^{32}$, publicándose centenares de tratados. De la lectura de muchos de ellos he podido extraer dos aseveraciones importantes:

Primera: en todos los casos, la práctica de la di/simulación estuvo acompañada -ni precedida, ni sucedida- de una más o menos compleja formulación teórica que pretende justificar y legitimar el empleo de esta técnica desde los ámbitos de la moral, la practicidad político-social y, naturalmente, la teología. En el caso de la di/simulación del Príncipe: el maquiavelismo, el tacitismo, la razón de estado... En el de la nobleza: la cortesía, la prudencia, la sprezzatura de Castiglione... En el de la di/simulación religiosa católica: la restricción mental, el casuismo jesuítico..., etc.

Estos constructos teóricos -segunda aseveración- son auténticos palimpsestos en los que confluyen, se mezclan y, a menudo confunden, conceptos e ideas de ambientes y tradiciones muy diversas.

${ }^{30}$ En 1616 Eustache de Refuge escribió que, si bien ésta es un arte especialmente útil para los cortesanos, «la dissimulation soit nécessaire à toutes sortes de personnes» (Traicté de la Cour ou Instruction des Courtisans, cap. XXXV de la Primera Parte).

${ }^{31}$ Para una introducción a este asunto véanse, entre otros: Cavaillé, Dis/simulations; Fernández-Santamaría, "Simulación y disimulación", pp. 741-770; Flor, Pasiones Frías: Secreto y Disimulación en el Barroco hispano; Ginzburg, Il Nicodemismo: simulazione e dissimulazione religiosa; Snyder, Dissimulation and the Culture of Secrecy in Early Modern Europe; Villari, Elogio della dissimulazione; Zagorin, Ways of Lying: Dissimulation, Persecution and Conformity in Early Modern Europe.

${ }^{32}$ Von Stackelberg, "Französische Moralistik im europaischen Kontext", p. 45. 
En el ánimo morisco debieron de influir los ejemplos y doctrinas de otras comunidades religiosas occidentales perseguidas, como los protestantes, los alumbrados y los católicos ingleses ${ }^{33}$. En este sentido, el precedente de los marranos españoles, obligados a ocultar su pasado y presente judío tras 1492, debió ser determinante. También debieron pesar las ya por entonces difundidas doctrinas sobre la di/simulación honesta en el ámbito de la tratadística política, que los moriscos pudieron ver reflejadas en la actitud de sus gobernantes y en sus no pocos contactos con la Corte $^{34}$. Con todo, creo que en el caso morisco el principal referente fue otro: la doctrina islámica de la taqiyya. Principal para los investigadores, por ser un elemento original y único en el paisaje ontológico cristiano-occidental. Principal, también, para los propios moriscos, pues les permitía justificar su actitud desde las propias bases teológicas del Islam y los dichos del Profeta, algo de suma relevancia si tenemos en cuenta que, de lo que se trataba en definitiva, era de determinar si su di/simulación sería perdonada por Alá el Día del Juicio (Yawm al-Qiyāma).

Discrepo de Bernard Vincent cuando dice que «la taqiyya, no es más que un mal menor ${ }^{35}$. Yo la considero un asunto fundamental. Creo que esta dispensación teológica fue «un mecanismo de auto-defensa

33 Ahora bien, decir que «los moriscos utilizaron el nicodemismo, como otros grupos religiosos, pero no la taqiyya» (Rubiera Mata, "Los moriscos como criptomusulmanes", pp. 545 y 547) equivale a no decir nada o a decir algo errado, por la confusión de conceptos. Hasta el día de hoy, la historiografía ha manejado dos acepciones distintas del término «nicodemismo»: una acepción histórica, más fiel al termino acuñado por Calvino, que se refiere a la disimulación religiosa practicada por algunos cripto-protestantes en Italia y Centroeuropa en el contexto de la Reforma y la Contrarreforma; y una segunda acepción, más coloquial, que vendría a designar la disimulación religiosa en un sentido amplio, sin atender a marco cronológico o geográfico alguno. Si manejamos la primera acepción -la más precisa y apropiada para el trabajo académico-, afirmar que «los moriscos utilizaron el nicodemismo» equivaldría a afirmar que éstos conocieron y se apropiaron de las doctrinas y justificaciones cristianas empleadas por los protestantes para justificar su disimulo. Un disparate. Si manejamos la segunda acepción, no decimos nada. Los moriscos emplearon ciertamente el nicodemismo -la disimulación religiosa- como otras minorías de occidente, pero eso no excluye que recurrieran a la taqiyya, que no es la práctica en sí, sino la doctrina que la justifica (para mayor detalle véase, por ejemplo, Zagorin, Ways of Lying, pp. 12-14; Cantimori, "Eretici italiani del Cinquecento", pp. 7-141 y Ginzburg, Il nicodemismo).

${ }^{34}$ Así lo denunciaban, ya en la época, el Padre Juan Useros (Compendio de la destruyçion de España, f. 182v) y Jaime Bleda (Crónica de los moros de España, pp. 54 y 869) entre otros.

${ }_{35}$ Vincent, El Río morisco, p. 136. 
no solamente jurídica y doctrinal sino una sutil fórmula de salubridad psíquica, por cuanto permitió la convivencia de los musulmanes practicantes con un entorno [...] hostill» ${ }^{36}$. Gracias a ella, los moriscos pudieron salvar la hacienda y la vida (di/simulando ante los cristianos) y pensar que, aun así, también salvarían el alma en la fe de sus padres y abuelos. El hecho de que todos los grupos sociales que han practicado la di/simulación a lo largo de la Historia hayan elaborado este tipo de justificaciones teóricas es un buen indicio de su importancia.

La condición sunní de los moriscos no es incompatible con la aceptación de esta doctrina, como tampoco lo es el hecho lingüístico de que no emplearan o conocieran el término taqiyya. La interpretación tradicional (ausencia de la palabra taqiyya en los textos, igual a ausencia de la noción entre los moriscos) es errónea por simplista. Cuando se analizan las fuentes, el buen historiador no debe limitarse a buscar el término concreto que estudia, sino el fenómeno que éste postula. Entre otras cosas porque los signos lingüísticos tienen la molesta costumbre de cambiar de significantes a lo largo del tiempo y el espacio, incluso cuando siguen apuntando hacia el mismo significado. Esta consideración es especialmente importante si tenemos en cuenta que, en el mundo islámico, la di/simulación prudencial no siempre estuvo ligada al término taqiyya; a menudo fue referida con otras palabras, como almudāfa 'a (autoprotección) ${ }^{37}$, jab' (escondido) $^{38}, j a w f(\text { temor })^{39} \mathrm{y}$, muy frecuentemente, kitmān (ocultamiento) ${ }^{40}$. Taqiyya es sólo una etiqueta - una de las muchas que existen-para referir la creencia musulmana que juzga legítimo fingir en asuntos de fe bajo determinadas circunstancias de peligro. Y si en el Oriente musulmán (un mundo de realidades político-sociales similares relativamente cohesionadas y conectadas entre sí), muchos grupos apelaron a ella sin emplear este término, no

${ }^{36}$ García Cruz, "El disimulo religioso en el ámbito doctrinal y legal islámico", pp. 661-672. Según Míkel de Epalza, la taqiyya era «une arme extraordinaire, tirée de l'arsenal de l'Islam contre le Mal, prévue, justement, pour des moments de grande difficulté...» ("Principes chrétiens et principes musulmans face au probleme morisque", p. 42).

${ }_{37}$ Así lo emplea, por ejemplo, Muḥammad Ibn Bābawayh (m. 940) en su al-Imāma wa-l-tabșira min al-hayra, pp. 9 y 18.

${ }^{38}$ Ib̀n Bābawayh, Ma'ānì al-ajbār, p. 159.

39 Al-Ŷạ̄ize, Risālat al- 'Uțmāniyya, p. 152.

40 Taqiyya y kitmān suelen emplearse como sinónimos, si bien el segundo parece aludir más al ocultamiento que al disimulo. Véanse éstas y otras referencias en Kohlberg, "Taqiyya in Shīei Theology", p. 346. 
es arriesgado pensar que en la España morisca, independiente y aislada de la Dār al-Islām durante siglos, ocurriese algo semejante.

Las fuentes cristianas citadas demuestran que los moriscos conocían la taqiyya, como también demuestran la gran permanencia que esta creencia tuvo en España. Citaré un ejemplo más al respecto, muy ilustrativo. Hacia 1727, la Inquisición descubrió en Granada la última gran comunidad cripto-musulmana de la que tengamos noticia. Se realizaron varias pesquisas y once autos de fe. Unas 250 personas fueron procesadas por «mahometismo» ${ }^{41}$. Sus opiniones religiosas quedaron plasmadas en dos fuentes: las alegaciones fiscales que se conservan en el Archivo Histórico Nacional y un cuadernillo titulado Errores de los moriscos de Granada escrito en aquellos mismos años ${ }^{42}$. En éste encontramos, de nuevo, una alusión a la taqiyya. Los reos confiesan haber practicado ritos musulmanes en secreto y haberse fingido católicos, y consideran legítima su doblez pues «decían que no se oponía a la secta de Mahoma el confesar y comulgar siempre que se ofreciera para cumplir con los christianos ${ }^{43}{ }^{\prime}$.

Es decir, ciento veinte años después de las expulsiones, seguía habiendo cripto-musulmanes en España que creían en la existencia de un principio islámico que consentía el disimulo en caso de peligro. Naturalmente, esta creencia no fue una isla. Se mezcló y confundió con otras doctrinas occidentales que también legitimaban la di/simulación. Unas y otras no se excluyen mutuamente, sino que se fusionan y convergen como los afluentes de un río. No en vano, todas (e)manan de la misma fuente: el hombre y su deseo atemporal de superar sus contradicciones.

${ }^{41}$ Véanse, entre otros, Lera García, "Criptomusulmanes ante la Inquisición granadina en el siglo XVIII", pp. 521-573; Lera García, "Gran ofensiva antijudía de la Inquisición de Granada", pp. 147-170; Vincent, "Le tribunal de Grenade", pp. 216-218 y García Ivars, La represión en el tribunal inquisitorial de Granada.

${ }_{42}$ Este documento fue publicado por María Soledad Carrasco Urgoiti y Míkel de Epalza en un artículo titulado "El manuscrito «Errores de los moriscos de Granada» (Un núcleo criptomusulmán del siglo XVIII)”, pp. 235-247.

${ }^{43}$ Errores de los moriscos de Granada, ff. 21r-21v. 


\section{Bibliografía}

Al- 'Āmilī, al-Hurr, Wasā'il al-Š́̀ 'a, Qom, Bayt Institute, 2004.

Amory, Frederic, "Whited Sepulchres. The Semantic History of Hypocrisy to the High Middle Ages”, Recherches de Théologie Ancienne et Médiévale, 53 (1956), pp. 5-17.

Ayala, Martín de, Catechismo para instruccion de los nueuamente conuertidos de moros... Impresso por orden del patriarcha de Antiochia y Arçobispo de Valencia Don Iuan de Ribera, Valencia, Pedro Patricio Mey, 1599.

Bleda, Crónica de los moros de España, Valencia, Felipe Mey, 1618.

Boronat y Barrachina, Pascual, Los moriscos españoles y su expulsión. Estudio histórico-crítico, Valencia, Impr. de F. Vives y Mora, 1901.

Bos, Jacques, "The Hidden self of the hypocrite", en Toon van Houdt et al., On the Edge of Truth and Honesty: Principles and Strategies of Fraud and Deceit in the Early Modern Period, Leiden-Boston, Brill, 2002, pp. 65-84.

Cantimori, D., "Eretici italiani del Cinquecento", en Eretici italiani del Cinquecento e altri scritti, Turín, Einaudi, 1992, pp. 7-141.

Cardaillac, Louis, Morisques et Chrétiens: un affrontement polémique (1492-1640), París, Klincksieck, 1977. Trad. castellana: Moriscos y cristianos: un enfrentamiento polémico: (1492-1640), Madrid, Fondo de Cultura Económica, 1979.

Cardaillac, Louis, "Un aspecto de las relaciones entre Moriscos y Cristianos: Polémica y “Taqiyya”, en A. Galmés (ed.) Actas del Coloquio Internacional sobre Literatura Aljamiada y Morisca, Madrid, Gredos, 1978, pp. 107-122 CLEAM.

Carrasco Urgoiti, María Soledad y Epalza, Mikel de, "El manuscrito «Errores de los moriscos de Granada» (Un núcleo criptomusulmán del siglo XVIII)”, Fontes Rerum Balearum, III (1979-1980), pp. 235-247.

Cassani, José, Glorias del segundo siglo de la Compañía de Jesús, Madrid, Manuel Fernández, 1734.

Cavaillé, Jean-Pierre, Dis/simulations. Jules-César Vanini, François La Mothe Le Vayer, Gabriel Naudé, Louis Machon et Torquato Accetto, Religion, morale et politique au XVII siècle, París, Honoré Champion, 2002.

Cavaillé, Jean-Pierre, "Simulatio/dissimulatio, notes sur feinte et occultation, XVIe-XVIIe siècle”, en M. Fattori (ed)., Il Vocabolario della Répúblique des Lettres, Firenze, Olschki, 1997, pp. 115-131.

Daftary, Farhad, The Ismailis: Their History and Doctrines, Cambridge, Cambridge University Press, 1992.

Dickson, Martin, Shah Tahmasp and the Uzbeks, tesis doctoral, Princeton, 1958.

Epalza, Mikel de, "Principes chrétiens et principes musulmans face au probleme morisque", en L. Cardaillac (ed.), Les Morisques et l'Inquisition, París, Publisud, 1990, pp. 37-50

Ernst, Carl, Words of Extasy in Sufism, Albany, State University of New York Press, 1985. 
Feria, Pedro de, Catecismo del Sacromonte y Doctrina Christiana de Fr. Pedro de Feria: conversión y evangelización de moriscos e indios, Luis Resines (ed.), Granada, CSIC, 2002.

Fernández-Santamaría, José A., "Simulación y disimulación: El problema de la duplicidad en el pensamiento político español del barroco", $B R A H$, t. 177, c. 1 (1980), pp. 741-770.

Flor, Fernando de la, Pasiones Frías: Secreto y Disimulación en el Barroco hispano, Madrid, Marcial Pons, 2005.

Fonseca, Damián, Iusta expulsión de los moriscos de España, con la instrucción, apostasía y traicion dellos: y respuesta a las dudas que se ofrecieron acerca desta materia, Roma, Iacomo Mascardo, 1612. Reed. Relación de la expulsión de los moriscos del Reino de Valencia, del M. Fr. Damián Fonseca. Publícala nuevamente la Sociedad valenciana de Bibliófilos, Valencia, M. Alufre, 1878. Reprod. de la ed. de 1612 en García García, Bernardo José (comp.), Obras clásicas sobre los Austrias. Siglo XVII, CD-ROM, Madrid, Fundación Histórica Tavera-Digibis, 1998.

García Cárcel, Ricardo, "Estudio crítico del catecismo de Ayala-Ribera”, en Louis Cardaillac (ed.), Les Morisques et leur temps. Table ronde internationale (Montpellier, 4-7 juillet 1981), París, CNRS, 1983, pp. 159-168.

García Cruz, José Fernando, "El disimulo religioso en el ámbito doctrinal y legal islámico", en De mudéjares a moriscos: una conversión forzada: actas, Teruel, Centro de Estudios Mudéjares, 2002, vol. 2, pp. 661-672.

García Ivars, Flora, La represión en el tribunal inquisitorial de Granada, 15501819, Madrid, Akal, 1991.

García Pedraza, Amalia, Actitudes ante la muerte en la Granada del siglo XVI: los moriscos que quisieron salvarse, Granada, Universidad, 2002.

Ginzburg, Carlo, Il Nicodemismo. Simulazione e dissimulazione religiosa nell'Europa del'500, Turín, Einaudi, 1970.

Guadalajara y Xavier, Marcos de, Memorable expulsión y iustíssimo destierro de los moriscos de España. Nuevamente compuesta y ordenada por F.Marco de Guadalajara i Xavierr, religioso y general historiador de la Orden de Nuestra Señora del Carmen Observante en la provincia de Aragón. Dirigida a los Catholicos y Serenissimos Principes de España, Don Phelipe Emmanuel, Don Carlos, y don Fernando de Austria, Pamplona, Nicolás de Assiayn, 1613.

Harvey, Leonard Patrick, "Crypto-Islam in Sixteenth Century Spain”, en Actas del Primer Congreso de Estudios Árabes e Islámicos, Madrid, Instituto Hispanoárabe de Cultura, 1964, pp. 163-178.

Harvey, Leonard Patrick, Muslims in Spain, 1500 to 1614, Chicago, Londres, University of Chicago Press, 2005.

Harvey, Leonard Patrick, "Una referencia explícita a la legalidad de la práctica de la taqiya por los moriscos", Sharq Al-Andalus, 12 (1995), pp. 561-564.

Houdt, Toon van, "Word Histories, and Beyond: Towards a Conceptualization of 
Fraud and Deceit in Early Modern Times", en Toon van Houdt et al. (eds.), On the Edge of Truth and Honesty: Principles and Strategies of Fraud and deceit in the Early Modern Period, Leiden-Boston, Brill, 2002, pp. 1-31.

Ibn Bābawayh, Muḥammad b. 'Alī, al-Imāma wa-l-tabṣira min al-ḥayra, Qom, s.e., 1984.

Ibn Bābawayh, Muhammad b. 'Alī, Ma'ānī ajbār, Naŷaf, s.e., 1971.

Jomeini, Ruhollāh, Risāla fì l-taqiyya, s.l., s.e., 1999.

Khan, Ruqayya Yasmine, Self and Secrecy in Early Islam, Columbia, University of South Carolina Press, 2008.

Kohlberg, Etan, "Taqiyya in Shī̄i Theology and Religion”, en Hans Kippenberg y Guy Stroumsa (eds.), Secrecy and Concealment: Studies in the History of Mediterranean and Near Eastern Religions, Leiden-Nueva York-Colonia, Brill, 1995, pp. 345-380.

Lera García, Rafael de, "Criptomusulmanes ante la Inquisición granadina en el siglo XVIII”, Hispania Sacra, 36 (1984), pp. 521-573.

Lera García, Rafael de, "Gran ofensiva antijudía de la Inquisición de Granada, 1715-1727”, Chronica Nova, 17 (1989), pp. 147-170.

Madelung, Wilferd, "The Spread of Maturidism and the Turks", en Actas do IV Congresso de Estudos Arabes e Islamicos, Coimbra-Lisboa, 1968, Leiden, Brill 1971, pp. 109-168.

Mancebo de Arévalo, Sumario de la relación y exercicio espiritual sacado y declarado por el mancebo de Arévalo en nuestra lengua castellana, Gregorio Fonseca Antuña (ed.), Madrid, Fundación Ramón Menéndez Pidal, 2002.

Al-Qurțubī, Abū `Abd Allāh Muhammad, al-Ŷāmi` li-ahkām al-Qur'ān, El Cairo, s.e., 1967.

Refuge, Eustache de, Traicté de la Cour ou Instruction des Courtisans, París, Chez Abraham Saugrain, 1617.

Rubiera Mata, María Jesús, "La taqiyya y la fatua del Muftí de Orán”, en Biblioteca Virtual Miguel de Cervantes, Alicante, s.e., 2001.

Rubiera Mata, María Jesús, "Los moriscos como criptomusulmanes y la Taqiyya", en IX Simposio Internacional de Mudejarismo. Actas, Teruel, Centro de Estudios Mudéjares, 2004, pp. 537-548.

Sabbagh, Leila, "La religion des Moriscos entre deux fatuas", en Louis Cardaillac (ed.), Les morisques et leur temps, París, CNRS, 1983, pp. 43-56.

Al-Sarajsī, al-Mabsūt, Beirut, Dār al-Ihyyā'.

Šayj al-Mufid, Tașhịh al-i`tiqād fi șawāb al-intiqād aw šarh 'aqā'id al-ṣadūq, Qom, s. e., 1984.

Schimmel, Annemarie, "Secrecy in Sufism”, en Kees Bolle (ed.), Secrecy in Religions, Leiden, Brill, 1987, pp. 81-102.

Snyder, John R., Dissimulation and the Culture of Secrecy in Early Modern Europe, Berkeley-Los Ángeles-Londres, University of California Press, 2009. 
Stackelberg, Jürgen von, Französische Moralistik im europäischen Kontext, Darmstadt, Wissenschaftliche Buchgesellschaft, 1982, Erträge der Forschung, 172.

Steigerwald, Diane, "La dissimulation (taqiyya) de la foi dans le shī'isme ismaélien”, Studies in Religion/Sciences religieuses, 27 (1988), pp. 39-59.

Stewart, Devin, "Documents and Dissimulation: Notes on the Performance of Taqiyya", en Cristina de la Puente (ed.), Identidades marginales, Madrid, CSIC, 2003, Estudios Onomástico-Biográficos de al-Andalus (EOBA) 13, pp. 569598.

Stewart, Devin, "Taqiyyah as Performance: the Travels of Bahā' al-Dīn al-'Āmilī in the Ottoman Empire (991-93/1583-85)", Princeton Papers in Near Eastern Studies, 4 (1996), pp. 1-70.

Straface, Antonella, "La Taqiyya nell'Islām: valenze e connotazioni”, Studi Magrebini, 26 (1998-2002), pp. 211-223.

Al-Ṭ̂ūī, Nașīr al-Dīn, Taljīṣ al-Muhașṣal, El Cairo, s. e., 1905-1906.

Valencia, Pedro de, Tratado acerca de los moriscos de España, 1606, recogido en Obras completas, Rafael González Cañal (dir.), León, Universidad, 1999, vol. IV, pp. 67-139.

Villari, Rosario, Elogio della dissimulazione. La lotta politica nel Seicento, Roma, Laterza, 1987.

Vincent, Bernard, "Le tribunal de Grenade", en Louis Cardaillac (ed.), Les Morisques et l'Inquisition, París, Publisud, 1990, pp. 216-218.

Vincent, Bernard, El río morisco, Valencia, Universidad de Valencia, 2006.

Al-Ŷāḥiz, Al- 'Uțmāniyya, 'Abd al-Salām Ḥārūn (ed.), El Cairo, Dār al-Kitāb al'arabī, 1955.

Zagorin, Perez, Ways of Lying : Dissimulation, Persecution and Conformity in Early Modern Europe, Cambridge-Londres, Harvard University Press, 1990.

Recibido: $21 / 02 / 2013$

Aceptado: 12/06/2013 